\title{
Oral microbiota maturation during the first 7 years of life in relation to allergy development
}

Majda Dzidic, Thomas Abrahamsson, A. Artacho, M. C. Collado, A. Mira and Maria J enmalm

The self-archived postprint version of this journal article is available at Linköping University Institutional Repository (DiVA):

http:// urn.kb.se/ resolve?urn=urn:nbn:se:liu:diva-152823

N.B.: When citing this work, cite the original publication.

Dzidic, M., Abrahamsson, T., Artacho, A., Collado, M. C., Mira, A., J enmalm, M., (2018), Oral microbiota maturation during the first 7 years of life in relation to allergy development, Allergy. European J ournal of Allergy and Clinical Immunology, 73(10), 2000-2011.

https:// doi.org/ 10.1111/ all.13449

Original publication available at:

https:// doi.org/ 10.1111/all.13449

Copyright: Wiley (12 months)

http:// eu.wiley.com/WileyCDA/ 
MRS. MAJDA DZIDIC (Orcid ID : 0000-0002-1131-4342)

Article type : Original Article: Experimental Allergy and Immunology

\section{Oral microbiota maturation during the first 7 years of life in relation to allergy development}

Short title: Oral microbiota maturation and allergy development

Majda Dzidic $\mathrm{MSc}^{1,2,3}$, Thomas Abrahamsson MD, $\mathrm{PhD}^{4}$, Alejandro Artacho $\mathrm{BSc}^{2}$, Maria Carmen Collado $\mathrm{PhD}^{1}$, Alex Mira $\mathrm{PhD}^{2}$ and Maria C Jenmalm, $\mathrm{PhD}^{* 3}$

\section{Affiliations:}

1. Institute of Agrochemistry and Food Technology (IATA-CSIC), Department of Biotechnology, Unit of Lactic Acid Bacteria and Probiotics, Valencia, Spain

2. Department of Health and Genomics, Center for Advanced Research in Public Health, FISABIO, Valencia, Spain; and CIBER-ESP, Madrid; Spain

3. Department of Clinical and Experimental Medicine, Division of Autoimmunity and Immune Regulation, Linköping University, Linköping, Sweden

4. Department of Clinical and Experimental Medicine, Division of Pediatrics, Linköping University, Linköping, Sweden

\section{Correspondence:}

*To whom correspondence may be addressed:

This article has been accepted for publication and undergone full peer review but has not been through the copyediting, typesetting, pagination and proofreading process, which may lead to differences between this version and the Version of Record. Please cite this article as doi: 10.1111/all.13449

This article is protected by copyright. All rights reserved. 


\section{Maria Jenmalm}

Address: Linköping University, Department of Clinical and Experimental Medicine, AIR/Clinical Immunology, 58185 Linköping, Sweden.

Email address: maria.jenmalm@liu.se

Phone number: +46 101034101

Fax +46-13-13 2257

Funding: Alex Mira: Spanish Ministry of Economy and Competitiveness (grant no. BIO2015-68711-R). Maria C. Jenmalm: The Swedish Research Council (2016-01698); the Swedish Heart and Lung Foundation (20140321); the Medical Research Council of Southeast Sweden (FORSS-573471); the Cancer and Allergy Foundation. Maria Carmen Collado: European Research Council (ERC-starting grant 639226).

Author contributions: T.R.A. and M.C.J. were responsible for sample collection and clinical evaluation of the children. A.M., M.C.J., and M.C.C., designed the study. M.D. performed the sample preparations, experimental work and analyses/presentation of the data. A.A., M.D. performed statistical analysis in R. All authors interpreted and discussed the results. M.D. drafted the manuscript. All authors contributed to and approved the final draft for publication. The authors declare no conflict of interest.

\section{ABSTRACT}

Background: Allergic diseases have become a major public health problem in affluent societies. Microbial colonization early in life seems to be critical for instructing regulation on immune system maturation and allergy development in children. Even though the oral cavity is the first site of encounter between a majority of foreign antigens and the immune system, the influence of oral bacteria on allergy development has not yet been reported.

Objective: We sought to determine the bacterial composition in longitudinally collected saliva samples during childhood in relation to allergy development.

This article is protected by copyright. All rights reserved. 
Methods: Illumina sequencing of the $16 \mathrm{~S}$ rDNA gene was used to characterize the oral bacterial composition in saliva samples collected at 3, 6, 12, 24 months and 7 years of age from children developing allergic symptoms and sensitization $(n=47)$ and children staying healthy $(n=33)$ up to seven years of age.

Results: Children developing allergic disease, particularly asthma, had lower diversity of salivary bacteria together with highly divergent bacterial composition at 7 years of age, showing a clearly altered oral microbiota in these individuals, likely as a consequence of an impaired immune system during infancy. Moreover, the relative amounts of several bacterial species, including increased abundance of Gemella haemolysans in children developing allergies and Lactobacillus gasseri and $L$. crispatus in healthy children, was distinctive during early infancy, likely influencing early immune maturation.

Conclusion: Early changes in oral microbial composition seem to influence immune maturation and allergy development. Future experiments should test the probiotic potential of $L$. gasseri and $L$. crispatus isolates.

Keywords: Allergy development, infancy, Gemella haemolysans, Lactobacillus, oral microbiota.

\section{INTRODUCTION}

During the past decades, allergic diseases have become a major public health problem in affluent societies.(1) Microbial colonization occurring early in life seems to be critical for instructing regulation on the maturation of the immune system and allergy development in children. $(2,3)$ Approximately 700 common microbial species have been detected in the oral cavity.(4) Typically, the commensal microbiota here have a symbiotic relationship with the host, although, under certain circumstances, some microbes can overcome host defences and become pathogenic.(5) At the birth and following hours, the infant's oral cavity is exposed to a large amount of microorganisms encountered through the birth canal and during breastfeeding, in the contact with parents and medical staff and through breathing.(6) Moreover, it has been observed that maternal intrapartum antibiotic administration contributed to the shaping of the microbial colonization pattern in the neonatal oral cavity.(7)

This article is protected by copyright. All rights reserved. 
During the initial period, the microbiota composition of different niches of the neonate's body highly resemble each other.(8) Niche specific establishment of a microbiota of increasing complexity then occurs, concurrent with immune system maturation.(9) However, relatively little is known about how the microbiome develops at extra-intestinal sites during infancy. As yet, there are no published longitudinal studies regarding oral microbiota development during early childhood with culture independent next generation sequencing methodology.

Accumulating evidence shows a close relationship between microbial dysbiosis during infancy and allergy development during childhood. $(2,3)$ Factors such as early life antimicrobial exposure(10), caesarean delivery(11), formula feeding(12) and maternal consumption of antimicrobials during pregnancy(13) have been identified to have capacity to influence microbial composition, thus potentially contributing to allergic disease development in childhood. Most of the studies present today are describing the microbial colonization in the gut $(3,9)$, yet there are also indications that microbial colonization of the skin $(14,15)$ and respiratory tract might be associated with allergies.(16) While some studies are demonstrating the bacterial dysbiosis and lower microbial diversity already before the onset of the allergic disease(14, 17-21), other are describing and comparing the differences in microbiota in children having allergies and being healthy.(15) Because the oral cavity is the first line of encounter between the immune system and the majority of foreign antigens, it is plausible to believe that the oral microbiota might have a crucial role in allergy development. While gut, skin and nasopharyngeal microbial dysbiosis during infancy has earlier been associated with the aberrant development of immune responses and allergy $(14,18,19)$, the influence of oral bacteria on allergy development has not yet been studied in longitudinal cohorts and needs to be further addressed.

In this study, we aimed to evaluate the longitudinal development of oral microbiota during infancy and childhood in saliva samples from children developing allergies and children staying healthy up to 7 years of age by using culture-independent next generation sequencing methodologies.

\section{METHODS}

For detailed methods, experimental protocols and statistical analyses, see the Methods section in this article's supplementary information.

This article is protected by copyright. All rights reserved. 


\section{Sample collection and study design}

The infants included in this study were part of a larger randomized double-blind trial in Southeastern Sweden, recruiting participants between 2001 and 2003, where the potential allergy prevention effect of probiotic Lactobacillus reuteri ATCC 55730 until 2 and 7 years of age was evaluated.(22, 23) Among the 188 infants completing the original study, longitudinal salivary samples, collected at 3, 6, 12 and 24 month and 7 years of age, in 47 children developing allergic disease and 33 children staying healthy up to 7 years of age were selected for this study. The selection was based on sample availability and a clear allergy diagnosis. Allergic disease included eczema, gastrointestinal allergy, asthma, allergic rhinoconjunctitivis (ARC) and allergic urticaria. All allergic children (having allergic symptoms) in the current study were also sensitized. Infants were regarded as sensitized if they had at least one positive skin prick test and/or detectable circulating allergen specific-IgE antibodies.(22, 23) Skin prick testing and circulating IgE antibodies analyses were performed for all the children of the cohort, including those that did not have any allergic symptoms, in order to determine their atopy status. Skin prick tests were performed on the volar aspects of the forearm with egg white, fresh skimmed cow milk, and standardized cat, birch, and timothy extracts at 6,12 , and 24 months, and 7 years of age (at this time point also peanut, house dust mite (Der p) and dog). Circulating IgE antibodies to egg white, cow's milk cod, wheat, peanut, and soybean, was analysed at 6,12, and 24 months of age.(23) Asthma diagnosis required at least one of following two criteria: 1. Doctor diagnosis and asthma symptoms and/or medication during the last 12 months; 2 . Wheeze or nocturnal cough and a positive reversibility test with spirometry. Please see the supplementary section for detailed information.

Possible confounders, such as mode of delivery, breastfeeding, probiotics supplementation, maternal allergy and antibiotics use during the first two years of age were obtained from medical records and questionnaires (Table 1). $90 \%$ and $77 \%$ of all the children included were exclusively breast-fed up to 1 and 3 months of age, respectively, and $96 \%$ were partially breastfed at 3 months of age. No infant received antibiotics before 1 month of age and one at 3 months of age.

The studies were approved by the Regional Ethics Committee for Human Research in Linköping, Sweden (Dnr 99323, M122-31 and M171-07, respectively). An informed consent was obtained from both parents before inclusion in the study.

This article is protected by copyright. All rights reserved. 


\section{DNA extraction and 16S rDNA gene amplification and sequencing}

DNA from 250 ul of saliva samples was isolated with a MagNA Pure LC 2.0 equipment (1996-2016 Roche Diagnostics, Barcelona, Spain), using MagNA Pure LC DNA Isolation Kit III for Bacteria \& Fungi (Roche Diagnostics $\mathrm{GmbH}$, Mannheim, Germany) following the manufacturer's instructions with additional enzymatic treatments. Extracted DNA was pre-amplified in order to increase total nucleic acid yield by using universal bacterial degenerate primers, encompassing the hypervariable regions V1-V5 of the gene. The DNA was sequenced on a MiSeq Sequencer according to manufacturer's instructions (Illumina).

\section{Bacterial load and measurements by quantitative PCR}

Total bacterial load (bacterial cells per $\mathrm{ml}$ of saliva) in saliva samples was measured by quantitative PCR using primers targeting 165 rDNA gene. Please see the Methods section in this article's supplementary information for more details.

\section{Bioinformatics and statistics}

Only overlapping paired-end reads were used for analysis. Sequences of $<250$ nucleotides in length were not considered; $5^{\prime}$ trimming was performed by cutting out nucleotides with a mean quality of $<30$ in 20-bp windows. Chimeric $16 \mathrm{~S}$ sequences were filtered out using USEARCH prior to taxonomical classification by RDP-classifier. Operational taxonomic units (OTUs) were generated by using CD-HIT OTU picking with $97 \%$ of similarity. The human oral microbiome database (HOMD) was used as a reference database for OTU assignment.

$\alpha$ - diversity analysis was utilized to estimate the samples' diversity and richness using the R-package Vegan. Constrained correspondence analysis (CCA) was used here to emphasize variation and bring out strong patterns in a dataset. This analysis was performed by $\mathrm{R}$ software ade4 package together with permutational multivariate analysis (Adonis) determining the differences in variance between groups.

Linear discriminant analysis effect size (LEfSe) was used to determine taxa, at both genus and species-level OTUs, that best characterize the populations of healthy children and children developing allergies. The plots obtained show the potential biomarkers in every group, ranked

This article is protected by copyright. All rights reserved. 
according to their effect size. The bars represent the effect size of differences observed for a particular taxon between groups, where the length of the bar represents a log10 transformed Linear Discriminant Analysis (LDA) score.

Statistical analyses were performed in R version 3.2.2 and GraphPad Prism 6 (GraphPad Software, San Diego, CA, USA, Version 6.1f), where $p<0.05$ was considered significant. Specific statistical tests are stated in figure legends. Sequences supporting the conclusions of this article are publicly available at the European Nucleotide Archive (ENA) database with the accession number PRJEB66628.

\section{RESULTS}

After quality filtering, 30,870,369 high-quality sequences were obtained, with an average of $92,700 \pm$ 3,652 (SEM) reads per sample.

\section{Bacterial diversity and density in saliva}

An overall increase in microbial diversity and richness was observed through time, reaching over 450 species at 7 years of age. Children developing allergic diseases had significantly lower bacterial diversity at 7 years, when compared with children staying healthy (Fig. $1 \mathrm{~A}, \mathrm{p}=0.037$ ). Moreover, a similar trend was observed at 7 years of age in children developing asthma (Fig. 1B, p=0.044). No significant differences were observed upon comparing species richness between children staying healthy and children developing allergic diseases during the first 7 years of age (Fig. 1C). However, children developing asthma tended to have higher bacterial richness at 12 and 24 months (Fig. 1D).

In subjects with allergies, the effect of asthma medication on microbiota diversity (using specieslevel OTUs), at 7 years of age was taken into account. When comparing healthy children and children developing allergies that were not taking asthma medication, a similar trend was observed (Shannon diversity index; Median $_{\text {Healthy }}=2.82$, Median $_{\text {Allergic }}=2.26, p=0.066$ ). As only four asthmatic children were not taking asthma medication at 7 years, this could not be statistically evaluated.

In order to better understand the progress of bacterial density through the children's age, the bacterial load (bacterial cells $/ \mathrm{ml}$ saliva) in saliva samples was measured. While there were no significant differences between children developing allergies/asthmatic symptoms and children

This article is protected by copyright. All rights reserved. 
staying healthy (Fig. S2), an overall growth of bacterial density was observed from 3 months to 7 years, reaching levels of $10^{8}$ bacterial cells $/ \mathrm{ml}$ saliva. Also, children developing allergic disease tended to have higher levels of bacterial load at 7 years of age $(p=0.054$, Fig. S2A), when compared to children staying healthy. Individuals with low or high bacterial load through time did not correspond to any of the clinical variables measured, such as sex, antibiotic use or probiotic supplementation.

\section{Microbial colonization patterns}

Adonis testing supported the clustering of children's oral microbiota according to time of development, giving significant p-values (Fig. 2). Furthermore, canonical correspondence analyses demonstrated that, during the first 2 years of life, no clear separation of microbial patterns between children staying healthy and children developing allergies was detected (Fig. 2A). However, differences in microbiota patterns appeared at 7 years of age between healthy and allergic children, and a similar trend was observed when including children having asthmatic symptoms only (Fig. 2B).

The LEfSe algorithm was applied for biomarker discovery. Bacterial genera that were increased in abundance in healthy children, as compared with children developing allergies during the first 7 years of age, were Eubacterium and Neisseria at 3 months (Fig. 3A), Lactobacillus, Alloprevotella, Corynebacterium, Selenomonas and Eubacterium at 6 months (Fig. 3B) and Lactobacillus, Selenomonas, Veillonella, Megasphera, Fusobacterium and Lachnoanaerobaculum at 7 years (Fig. 3C). Genera that were associated with allergy development were Bacteroides at 3 months and Gemella at 7 years (Fig.3 A/C).

Bacterial genera that were increased in abundance in children developing asthmatic symptoms as compared with healthy children were Alloprevotella at 12 months of age (Fig. 4A) and Staphylococcus at 24 months of age (Fig. 4B). Upon checking the staphylococci species present (hits with $>97 \%$ of identity over at least 350 bp alignment length), S. capitis (79\% of the Staphylococcus sequences), S. hominis (15\%) and S. warneri (4\%) were the most abundant. Bacterial genera that were increased in abundance in healthy children were Lactobacillus and Atopobium at 24 months of age (Fig. 4B) and Fusobacterium, Capnocytophaga, Lactobacillus and Streptococcaceae at 7 years of age (Fig. 4C).

This article is protected by copyright. All rights reserved. 


\section{Microbial species biomarkers}

The differences in bacterial composition between children staying healthy and children developing allergies and/or asthma were further evaluated at species-level OTUs ( $>97 \%$ of nucleotide identity) by using LefSe for biomarker discovery. At 3 months of age (Fig. 5A), bacterial species that were significantly increased in abundance in children staying healthy until 7 years were, among others, Prevotella sp. and Neisseria mucosa/sicca/flava, while Streptococcus parasanguinis and Gemella haemolysans were more prevalent in children developing allergies. At 6 months (Fig. 5B), Bacteroidales [G-2] sp. and Corynebacterium matruchotii were some of the bacteria that were observed in increased abundance in children staying healthy, while Streptococcus salivarius/cristatus/vestibularis and Selenomonas $s p$. were associated with allergy development. At one and two years, Veillonella dispar, Lactobacillus gasseri and Neisseria oralis/flava/mucosa were among bacterial species that were increased in abundance in children staying healthy (Fig. 5C-D). At the same time point, OTUs belonging to the genera Gemella (including G. sanguinis and $G$. haemolysans) and Streptococcus (including S. mitis/dentisani, S. lactarius and S. cristatus), as well as Alloprevotella sp. were associated with allergy development (Fig. 5C-D). At 7 years of age (Fig. 5E), Gemella haemolysans, Prevotella sp. and Streptococcus lactarius were associated with allergy development, while the larger diversity detected in healthy children at this age was reflected in a larger list of over-represented species, including Prevotella salivare, Veillonella rogosae and Lactobacillus gasseri.

It was also of interest to compare microbial biomarkers between children staying healthy and children developing asthmatic symptoms (Fig. 6) showing that Lactobacillus crispatus and L. gasseri were found in increased abundance in children staying healthy at different time points during that 7year period.

\section{Influencing factors}

The CCA statistic tool was used to examine the influence of confounding factors on microbial colonization patterns. No effect of delivery mode, antibiotic treatments, partial breastfeeding and maternal allergy on microbial composition in children developing allergies or asthmatic symptoms could be observed (data not shown). However, probiotic supplementation with L. reuteri ATCC 55730 during the first year of age appeared to influence the association of microbial composition with asthma, but not allergy development, at 12 months, 24 months and 7 years of age (Fig. S2;

This article is protected by copyright. All rights reserved. 
$\mathrm{p}=0.0083$, Adonis permutational analysis).

\section{DISCUSSION}

Given that the oral cavity is the first site of encounter between a majority of foreign antigens and the immune system, it is plausible that oral microbiome maturation might influence allergy development during childhood. In the present study, we use cultivation-independent techniques to characterise the development of microbial oral communities during the first 7 years of life in 33 healthy children and 47 children that developed allergic symptoms.

Development of allergic disease during childhood, and particularly asthma, was associated with a significantly lower bacterial diversity at 7 years of age. In comparison to gut microbiota studies where children developing allergic disease tend to have lower bacterial diversity than healthy children already during the first months of life $(17,20,21)$, the association of disease with oral microbiota diversity appears to increase with age. Likely, the diverse intestinal microbiota might be of great importance for a primary establishment and for maturation of a balanced postnatal innate and adaptive immunity. However, this study suggests that infant oral microbiota composition, including the abundance of $G$. haemolysans in children developing allergic symptoms and $L$. gasseri and L. crispatus in children staying healthy, is more important than the oral microbiota diversity for later allergy development. Oral cavity development during infancy was accompanied by an overall steady increase in both diversity and richness of the oral microbiome, reaching 300 OTUs and bacterial densities of $10^{6}$ cells $/ \mathrm{ml}$ saliva already at three months of age. Further oral microbiota acquirement is probably facilitated by microbial colonization through diet and transmission from parents, caregivers and siblings.(6) Even though children developing allergies and asthmatic symptoms tended to have higher species richness and bacterial load, specifically after the first year of life, in comparison to children staying healthy, no statistically significant differences during the first 7 years of life could be observed. The deficient mucosal immune system of the oral cavity may favour an altered species colonization, even for those species appearing at low abundance.

Increased abundances of the genus Bacteroides at 3 months of age and Gemella at 7 years were associated with allergy development. The identification of disease-associated bacteria, especially at an early age, could provide potential biomarkers of allergy risk. Bacteroides species are among the earliest-colonizing and one of the most numerically dominant commensals of the gut microbiota. $(2$, 4) They provide many beneficial effects to the host, including breakdown of complex dietary

This article is protected by copyright. All rights reserved. 
carbohydrates and modulation of mucosal glycosylation, and immune maturation.(24) However, Bacteroides is not a common oral inhabitant under healthy circumstances.(4) In addition, as these bacteria are potent stimulators of the immune system, the host immune responses can differ between the immunomodulatory molecules from different species of Bacteroides(25), possibly leading to aberrant immune development. Gemella is a predominant genus of the mucosal epithelium $(4,26)$ and in this study, it was related to allergy development in saliva samples particularly collected at 7 years of age, while at species level $G$. haemolysans was found to be associated with allergy development not only at 7 years of age, but also at 2 years, 1 year, and as early as 3 months of age. G. haemolysans has previously been shown to produce human IgA1 protease activity(27), a feature that is unique to this species within the genus Gemella, suggesting that its potential use as an early diagnostic marker in altered mucosal immunity deserve further investigation.

The primary colonizers of the oral microbiota, including both mucosal and tooth surfaces, are commonly streptococci, accounting for approximately $80 \%$ of early biofilms.(6) Most oral streptococci are commensal, frequently acquired during breastfeeding(28), although some are known to cause infective endocarditis when disseminated through the blood stream.(29) We observed that S. parasanguinis, a member of viridans streptococci(30), and S. lactarius, belonging to the $S$. mitis group(31), were here associated with allergy development in saliva samples from 3,12 , 24 months and 7 years of age. Both of these species have been described as primary colonizers, with S. parasanguinis frequently found in the tongue dorsum(26) and S. lactarius isolated from breast milk of healthy women.(32) Moreover, children developing asthmatic manifestations also had higher abundance of several Streptococci, including S. sanguinis (at 6 months), $S$. salivarius/vestibularis and S. cristatus (at 24 months) and S. australis and S. mitis at 7 years. Early asymptomatic colonization of the nasopharynx with Streptococcus, during infancy, has been proposed as a strong asthma predictor.(19) Because pioneer colonizers may facilitate the environment for later colonizers, the initial competition for bacterial colonization might have direct implications for the spatial and temporal composition of the developing oral microbiome, and therefore play a crucial role in immune modulation.

Neisseria sicca/mucosa/flava were increased in abundance in children staying healthy. The genus Neisseria is an abundant member of the oropharyngeal flora(33), tongue, oral mucosa and dental

This article is protected by copyright. All rights reserved. 
plaque(26). Furthermore, higher abundance of Corynebacterium at 6 months of age and the species C. matruchotii at 7 years of age were observed in children staying healthy, as compared with children developing allergy. Corynebacterium, particularly C. matruchotii, with its highly interactive filamentous structure is considered instrumental in oral biofilm architecture.(34) Members of this genus have been shown to utilize carbohydrates and metabolize lactate and acetate, likely maintaining $\mathrm{pH}$ homeostasis in a healthy oral biofilm.(35)

Children staying healthy up to 7 years had higher abundance of Lactobacillus both at genus and species level at 3, 6 and 24 months and 7 years when compared to children developing asthmatic symptoms, or to children developing allergies (at 24 months and 7 years). Lactobacilli colonize the gastrointestinal tract, including the oral cavity(36), and vagina(37), and may promote health by their influence on biofilm microbial composition, or by stimulating the host immune responses.(3) $L$. crispatus and L. gasseri were both associated with reduced allergy development. Lactobacillus gasseri is an important health-promoting immunomodulator of innate and systemic immune responses with an antimicrobial activity(38), and it has also been evaluated as a possible treatment of allergic rhinitis(39), demonstrating that supplementation with L. gasseri may be beneficial because of its effect on nasal blockage(39), and decreased nasal clinical symptoms scores in children suffering from allergic rhinitis.(40) As L. crispatus and L. gasseri were also observed to suppress allergic responses(41) and reduce mite-induced airway inflammation and hyperresponsiveness in mice models(42), these species may have a protective role in asthma development and deserve to be further investigated.

The use of antibiotics during the first years of life, birth mode, feeding habits and urban versus farm living have all been shown to affect microbiota composition(43), and several studies have found associations between these factors and allergy development.(3) To understand how these early-life risk factors may be related to allergy development during childhood, it is of great importance to consider how they affect the microbiome development in early infancy. Delivery mode, breastfeeding duration, antibiotics intake and maternal allergy seem not to have influence on the microbiota in relation to allergy and asthma development in our study population because the discovered differences are driven by health status (e.g. if children developed allergies or stayed healthy). However, the majority of the infants were exclusively breastfed until 3 months of age (Table 1), upon the first collection of the saliva samples, making it difficult to demonstrate the 
possible differences between breastfed and not breastfed infants due to low statistical power. Supplementation with $L$. reuteri during the first year of life seemed to influence the association between oral microbiota composition and asthma development (Fig. S2). This was reflected in distinctive microbiota clustering at 12 and 24 months and 7 years of age between children taking probiotics and not developing asthma and children that did not take probiotics and developed asthma. However, the probiotic intervention in this study did not directly reduce asthma development in the cohort. Reduced allergen responsiveness have previously been observed in $L$. reuteri supplemented infants, suggesting enhanced capacity for immunoregulation during infancy(44), associated with reduced incidence of IgE-associated eczema in infancy.(22) L. reuteri colonizes in a close contact with intestinal mucosa, priming dendritic cells to produce increased levels of anti-inflammatory IL-10 and inhibit the proliferation of bystander effector T-cells.(45) This species may have a similar mode of action in the oral mucosa, beside its symbiotic relationship with the immune system, and may support the co-colonization of other oral microbes beneficial for immune system development. However, larger studies, including the replication of our findings in other geographic origins, are required to further investigate and confirm the role of L. reuteri in allergy development. Beside saliva samples, it would be interesting to address other oral habitats, including tongue dorsum and buccal mucosa, in order to obtain the overall picture of oral microbiota maturation. Even though the time between 24 months and 7 years of age might be important to address in this type of longitudinal studies, the majority of the studies published today are describing that the first year of life is primarily significant for the immune system development.

\section{CONCLUSION}

By 7 years of age, allergic children appear to have a higher density and lower diversity of salivary bacteria, as well as a highly divergent bacterial composition, showing a clearly altered oral microbiota in these individuals, likely a consequence of an impaired immune system. Several individual bacterial species during infancy were associated with allergy development. The bacterial species detected in the current study as clearly associated to allergic conditions even years before the appearance of allergic manifestations, could potentially be used as early biomarkers capable to predict the risk of allergy and asthma. In addition, the possibility that some of these early changes in microbiota composition could impact immune modulation, inflammation and allergy development should be considered. Thus, the potential immunomodulatory effect of oral microorganisms deserves further attention and future investigation in longitudinal and animal-model studies.

This article is protected by copyright. All rights reserved. 
Table 1. Descriptive data of children included in the study.

*The $x^{2}$ test was used to detect potential differences in frequencies between children developing allergic/asthmatic symptoms and children staying healthy, except when the expected frequency for any cell was $<5$, in which case the Fisher exact test was used. $\mathrm{N}_{\text {Healthy }}=33, \mathrm{~N}_{\text {Allergic }}=47, \mathrm{~N}_{\text {Asthmatic }}=20$

Fig. 1. Species richness and diversity of the total microbiota in infant saliva samples of children developing allergies and children staying healthy up to 7 years of age. Bacterial richness and diversity (here presented by Chao1 and Shannon estimate indices at OTU level), obtained at different time points until 7 years of age, were determined by $16 s$ rDNA Illumina sequencing. (A) and (C) are describing bacterial diversity and richness, respectively, during the first 7 years of life in children staying healthy and children developing allergies. (B) and (D) are presenting species diversity and richness in children developing asthma and children staying healthy up to 7 years of age. Data are presented with mean and standard error. ( ${ }^{*} p<0.05$; Mann-Whitney U-test). 3 months $\left(N_{\text {Healthy }}=28 ; N_{\text {Allergic }}=36 ; N_{\text {Asthmatic }}=20\right), 6$ months $\left(N_{\text {Healthy }}=31 ; N_{\text {Allergic }}=45 ; N_{\text {Asthmatic }}=20\right), 12$ months $\left(N_{\text {Healthy }}=27 ; N_{\text {Allergic }}=35 ; N_{\text {Asthmatic }}=16\right), 24$ months $\left(N_{\text {Healthy }}=25 ; N_{\text {Allergic }}=34 ; N_{\text {Asthmatic }}=15\right)$ and 7 years of age $\left(N_{\text {Healthy }}=32 ; N_{\text {Allergic }}=40 ; N_{\text {Asthmatic }}=15\right)$.

Fig. 2. Salivary microbiota colonization patterns in children developing allergies and children staying healthy up to 7 years of age. Constrained correspondence analyses (CCA), here used to emphasize variations in microbiota species-level patterns, show compositional characteristics of total microbiota at different time points. The percentage of variation explained by constrained correspondence components is indicated on the axes. (A) Microbial composition differences in saliva of infants staying healthy and infants developing allergies during the first 7 years of age $(p=0.001)$. (B) Microbial composition patterns of salivary samples in children developing asthmatic symptoms and children staying healthy up to 7 years of age $(p=0.004)$. Different colours represent different time points ( $M=$ Months, $Y=Y$ ears). $p$ values for CCA plots were determined by Adonis and indicate if the factor provided (in this case time) can significantly explain data variability. Sample sizes were: 3 months $\left(N_{\text {Healthy }}=28 ; N_{\text {Allergic }}=36 ; N_{\text {Asthmatic }}=20\right), 6$ months $\left(N_{\text {Healthy }}=31 ; N_{\text {Allergic }}=45 ; N_{\text {Asthmatic }}=20\right), 12$ months $\left(N_{\text {Healthy }}=27\right.$; $\left.N_{\text {Allergic }}=35 ; \quad N_{\text {Asthmatic }}=16\right), 24$ months $\left(N_{\text {Healthy }}=25 ; N_{\text {Allergic }}=34 ; N_{\text {Asthmatic }}=15\right) ; 7$ years of age $\left(N_{\text {Healthy }}=32\right.$; $\left.\mathrm{N}_{\text {Allergic }}=40 ; \mathrm{N}_{\text {Asthmatic }}=15\right)$.

Fig. 3. Salivary bacterial genera associated with allergy development during the first 7 years of age. The plots show statistically significant genera associated with allergy development at (A) 3 months, (B) 6 months and 7 years of age (C). The LEfSe algorithm was used for biomarker discovery and the threshold for logarithmic discriminant analysis (LDA) score was 2. Sample sizes: 3 months $\left(N_{\text {Healthy }}=28 ; N_{\text {Allergic }}=36\right), 6$ months $\left(N_{\text {Healthy }}=31\right.$; $\left.\mathrm{N}_{\text {Allergic }}=45\right)$, and 7 years of age $\left(\mathrm{N}_{\text {Healthy }}=32 ; \mathrm{N}_{\text {Allergic }}=40\right)$.

Fig. 4. Salivary bacterial genera associated with asthma development during the first 7 years of life. (A) At 12 months of age only the genus Alloprevotella was increased in abundance in children developing allergies. (B)

This article is protected by copyright. All rights reserved. 
Genera associated with children developing allergies (grey) and children staying healthy (orange) at 24 months of age. (C) At 7 years of age, all significant differences corresponded to bacteria associated with healthy children. The LEfSe algorithm was used for biomarker discovery and the threshold for logarithmic discriminant analysis (LDA) score was 2 . Sample sizes were: 12 months ( $\left.N_{\text {Healthy }}=27 ; N_{\text {Asthmatic }}=16\right), 24$ months $\left(N_{\text {Healthy }}=25\right.$; $\left.\mathrm{N}_{\text {Asthmatic }}=15\right)$ and 7 years of age $\left(\mathrm{N}_{\text {Healthy }}=32 ; \mathrm{N}_{\text {Asthmatic }}=15\right)$.

Fig. 5. Salivary bacterial OTUs associated with allergy development during the first 7 years of life. Bars represent bacterial species at 3 (A), 6 (B), 12 (C) and 24 (D) months, and at 7 years (E) of age increased in abundance in children developing allergies (grey) and children staying healthy (orange). The LEfSe algorithm was used for biomarker discovery and the threshold for logarithmic discriminant analysis (LDA) score was 2. Sample sizes were: 3 months ( $\left.N_{\text {Healthy }}=28 ; N_{\text {Allergic }}=36\right), 6$ months $\left(N_{\text {Healthy }}=31 ; N_{\text {Allergic }}=45\right), 12$ months $\left(N_{\text {Healthy }}=27 ; N_{\text {Allergic }}=35\right), 24$ months $\left(N_{\text {Healthy }}=25 ; N_{\text {Allergic }}=34\right)$ and 7 years of age $\left(N_{\text {Healthy }}=32 ; N_{\text {Allergic }}=40\right)$.

Fig. 6. Salivary bacterial OTUs associated with asthma development during the first 7 years of life. Bars show bacterial species at 3 (A), 6 (B), 12 (C) and 24 (D) months and 7 years (E) of age increased in abundance in children developing asthmatic symptoms (grey) and children staying healthy (orange). The LEfSe algorithm was used for biomarker discovery and the threshold for logarithmic discriminant analysis (LDA) score was 2. Sample sizes were: 3 months ( $\left.N_{\text {Healthy }}=28 ; N_{\text {Asthmatic }}=20\right), 6$ months $\left(N_{\text {Healthy }}=31 ; N_{\text {Asthmatic }}=20\right), 12$ months $\left(N_{\text {Healthy }}=27\right.$; $\left.N_{\text {Asthmatic }}=16\right), 24$ months $\left(N_{\text {Healthy }}=25 ; N_{\text {Asthmatic }}=15\right)$ and 7 years of age $\left(N_{\text {Healthy }}=32 ; N_{\text {Asthmatic }}=15\right)$.

\section{Acknowledgements}

We would like to acknowledge the technical assistance performed by Ann-Marie Fornander and Camilla Janefjord.

Conflicts of interest: Maria C. Jenmalm: has received funding for a clinical trial and honoraria for lectures from BioGaia $A B$, as well as consultant fees and travel support from Nutricia/ Danone.

\section{REFERENCES}

This article is protected by copyright. All rights reserved. 
1. Pawankar R (2014) Allergic diseases and asthma: a global public health concern and a call to action. World Allergy Organ J 7:12.

2. Jenmalm MC (2017) The mother-offspring dyad: microbial transmission, immune interactions and allergy development. J. Intern. Med.

3. West CE, Dzidic M, Prescott SL, Jenmalm MC (2017) Bugging allergy; role of pre-, pro- and synbiotics in allergy prevention. Allergol. Int.

4. Huttenhower C, Gevers D, Knight R, et al (2012) Structure, function and diversity of the healthy human microbiome. Nature 486:207-214.

5. Arbes SJ, Matsui EC (2011) Can oral pathogens influence allergic disease? J Allergy Clin Immunol 127:1119-1127.

6. Gomez A, Nelson KE (2017) The Oral Microbiome of Children: Development, Disease, and Implications Beyond Oral Health. Microb Ecol 73:492-503.

7. Gomez-Arango LF, Barrett HL, McIntyre HD, et al (2017) Antibiotic treatment at delivery shapes the initial oral microbiome in neonates. Sci Rep 7:43481.

8. Dominguez-Bello MG, Costello EK, Contreras M, et al (2010) Delivery mode shapes the acquisition and structure of the initial microbiota across multiple body habitats in newborns. Proc Natl Acad Sci U S A 107:11971-5.

9. Gensollen T, lyer SS, Kasper DL, Blumberg RS (2016) How colonization by microbiota in early life shapes the immune system. Science (80- ) 352:539 LP-544.

10. Johnson CC, Ownby DR, Alford SH, et al (2005) Antibiotic exposure in early infancy and risk for childhood atopy. J Allergy Clin Immunol 115:1218-1224.

11. Jakobsson HE, Abrahamsson TR, Jenmalm MC, et al (2014) Decreased gut microbiota diversity, delayed Bacteroidetes colonisation and reduced Th1 responses in infants delivered by Caesarean section. Gut 63:559-566.

12. Guaraldi F, Salvatori G (2012) Effect of breast and formula feeding on gut microbiota shaping in newborns. Front Cell Infect Microbiol 2:94.

13. Stensballe LG, Simonsen J, Jensen SM, et al (2013) Use of Antibiotics during Pregnancy Increases the Risk of Asthma in Early Childhood. J Pediatr 162:832-838.e3.

14. Kennedy EA, Connolly J, Hourihane JO, et al (2017) Skin microbiome before development of atopic dermatitis: Early colonization with commensal staphylococci at 2 months is associated with a lower risk of atopic dermatitis at 1 year. J Allergy Clin Immunol 139:166-172.

15. Kong HH, Oh J, Deming C, et al (2012) Temporal shifts in the skin microbiome associated with disease flares and treatment in children with atopic dermatitis. Genome Res 22:850-859.

16. Huang YJ (2015) The respiratory microbiome and innate immunity in asthma. Curr Opin Pulm Med 21:27-32.

This article is protected by copyright. All rights reserved. 
17. Abrahamsson TR, Jakobsson HE, Andersson AF, et al (2014) Low gut microbiota diversity in early infancy precedes asthma at school age. Clin Exp Allergy 44:842-850.

18. Dzidic M, Abrahamsson TR, Artacho A, et al (2017) Aberrant IgA responses to the gut microbiota during infancy precede asthma and allergy development. J Allergy Clin Immunol 139:1017-1025.e14.

19. Teo SM, Mok D, Pham K, et al (2015) The infant nasopharyngeal microbiome impacts severity of lower respiratory infection and risk of asthma development. Cell Host Microbe 17:704-15.

20. Arrieta M-C, Stiemsma LT, Dimitriu PA, et al (2015) Early infancy microbial and metabolic alterations affect risk of childhood asthma. Sci Transl Med 7:307ra152-307ra152.

21. Abrahamsson TR, Jakobsson HE, Andersson AF, et al (2012) Low diversity of the gut microbiota in infants with atopic eczema. J Allergy Clin Immunol 129:434-440.

22. Abrahamsson TR, Jakobsson T, Böttcher MF, et al (2007) Probiotics in prevention of IgEassociated eczema: A double-blind, randomized, placebo-controlled trial. J Allergy Clin Immunol 119:1174-1180.

23. Abrahamsson TR, Jakobsson T, Björkstén B, et al (2013) No effect of probiotics on respiratory allergies: a seven-year follow-up of a randomized controlled trial in infancy. Pediatr Allergy Immunol 24:556-561.

24. Hooper L V., Wong MH, Thelin A, et al (2001) Molecular Analysis of Commensal HostMicrobial Relationships in the Intestine. Science (80- ) 291:881-884.

25. Berezow AB, Ernst RK, Coats SR, et al (2009) The structurally similar, penta-acylated lipopolysaccharides of Porphyromonas gingivalis and Bacteroides elicit strikingly different innate immune responses. Microb Pathog 47:68-77.

26. Eren AM, Borisy GG, Huse SM, Mark Welch JL (2014) Oligotyping analysis of the human oral microbiome. Proc Natl Acad Sci U S A 111:E2875-84.

27. Lomholt JA, Kilian M (2000) Immunoglobulin A1 protease activity in Gemella haemolysans. J Clin Microbiol 38:2760-2.

28. Boix-Amorós A, Collado MC, Mira A (2016) Relationship between Milk Microbiota, Bacterial Load, Macronutrients, and Human Cells during Lactation. Front Microbiol 7:492.

29. Mathews MJ, Mathews EH, Mathews GE (2016) Oral health and coronary heart disease. BMC Oral Health 16:122.

30. Geng J, Chiu C-H, Tang P, et al (2012) Complete Genome and Transcriptomes of Streptococcus parasanguinis FW213: Phylogenic Relations and Potential Virulence Mechanisms. PLoS One 7:e34769.

31. Aas JA, Griffen AL, Dardis SR, et al (2008) Bacteria of dental caries in primary and permanent teeth in children and young adults. J Clin Microbiol 46:1407-17.

This article is protected by copyright. All rights reserved. 
32. Martín V, Mañes-Lázaro R, Miguel Rodríguez J, Maldonado-Barragá A (2011) Streptococcus lactarius sp. nov., isolated from breast milk of healthy women. Int J Syst Evol Microbiol 61:1048-1052.

33. Liu G, Tang CM, Exley Correspondence RM, William S Non-pathogenic Neisseria: members of an abundant, multi-habitat, diverse genus.

34. Ferrer MD, Mira A (2016) Oral Biofilm Architecture at the Microbial Scale. Trends Microbiol 24:246-248.

35. Gross EL, Leys EJ, Gasparovich SR, et al (2010) Bacterial $16 \mathrm{~S}$ sequence analysis of severe caries in young permanent teeth. J Clin Microbiol 48:4121-8.

36. Lif Holgerson P, Harnevik L, Hernell O, et al (2011) Mode of birth delivery affects oral microbiota in infants. J Dent Res 90:1183-8.

37. Kamińska D, Gajecka M (2017) Is the role of human female reproductive tract microbiota underestimated? Benef Microbes 8:327-343.

38. Selle K, Klaenhammer TR (2013) Genomic and phenotypic evidence for probiotic influences of Lactobacillus gasseri on human health.

39. Kawase M, He F, Kubota A, et al (2009) Effect of fermented milk prepared with two probiotic strains on Japanese cedar pollinosis in a double-blind placebo-controlled clinical study. Int J Food Microbiol 128:429-434.

40. Chen Y-S, Lin Y-L, Jan R-L, et al (2010) Randomized placebo-controlled trial of lactobacillus on asthmatic children with allergic rhinitis. Pediatr Pulmonol 45:1111-1120.

41. Tobita K, Yanaka H, Otani H (2010) Anti-allergic effects of Lactobacillus crispatus KT-11 strain on ovalbumin-sensitized BALB/c mice. Anim Sci J 81:699-705.

42. Hsieh M-H, Jan R-L, Wu LS-H, et al (2017) Lactobacillus gasseri attenuates allergic airway inflammation through PPARY activation in dendritic cells. J Mol Med 1-13.

43. Rodríguez JM, Murphy K, Stanton C, et al (2015) The composition of the gut microbiota throughout life, with an emphasis on early life. Microb Ecol Health Dis 26:10.3402/mehd.v26.26050.

44. Forsberg A, Abrahamsson TR, Björkstén B, Jenmalm MC (2013) Pre- and post-natal Lactobacillus reuteri supplementation decreases allergen responsiveness in infancy. Clin Exp Allergy 43:434-442.

45. Smits HH, Engering A, van der Kleij D, et al (2005) Selective probiotic bacteria induce IL-10producing regulatory $\mathrm{T}$ cells in vitro by modulating dendritic cell function through dendritic cell-specific intercellular adhesion molecule 3-grabbing nonintegrin. J Allergy Clin Immunol 115:1260-1267.

This article is protected by copyright. All rights reserved. 
Table 1. Descriptive data of children included in the study

\begin{tabular}{|c|c|c|c|c|c|}
\hline Children & $\begin{array}{l}\text { Healthy (\% } \\
\text { [no.]) }\end{array}$ & $\begin{array}{c}\text { Developing } \\
\text { allergy } \\
\text { (\% [no.]) }\end{array}$ & $P$ value* & $\begin{array}{c}\text { Developing } \\
\text { asthma } \\
\text { (\% [no.]) }\end{array}$ & P value* \\
\hline Girls & 57 (19) & $51(24)$ & 0.57 & $70(14)$ & 0.40 \\
\hline Caesarean delivery & $15(5)$ & $13(6)$ & 0.75 & $20(4)$ & 0.72 \\
\hline \multicolumn{6}{|l|}{ Breastfeeding } \\
\hline 1 month exclusive & $93(31)$ & $87(41)$ & 0.46 & $90(18)$ & 0.63 \\
\hline 3 months exclusive & $76(25)$ & $79(37)$ & 0.91 & $70(14)$ & 0.53 \\
\hline 3 months partially & $100(33)$ & $94(44)$ & 0.26 & 95 (19) & 0.38 \\
\hline 12 months partially & $21(7)$ & $21(10)$ & 0.99 & $10(2)$ & 0.46 \\
\hline \multicolumn{6}{|l|}{ Antibiotic treatment } \\
\hline first year & $30(10)$ & $30(14)$ & 0.96 & $40(8)$ & 0.47 \\
\hline second year & $48(16)$ & $43(20)$ & 0.60 & $65(13)$ & 0.25 \\
\hline \multicolumn{6}{|l|}{ Day care } \\
\hline first year & $12(4)$ & $4(2)$ & 0.22 & $5(1)$ & 0.64 \\
\hline second year & $76(25)$ & $72(34)$ & 0.73 & $90(18)$ & 0.29 \\
\hline Probiotic group & 55 (17) & $45(21)$ & 0.55 & $50(10)$ & 0.91 \\
\hline
\end{tabular}

*The $x^{2}$ test was used to detect potential differences in frequencies between children developing allergic/asthmatic symptoms and children staying healthy, except when the expected frequency for any cell was $<5$, in which case the Fisher exact test was used. $N_{\text {Healthy }}=33, N_{\text {Allergic }}=47, N_{\text {Asthmatic }}=20$

This article is protected by copyright. All rights reserved. 

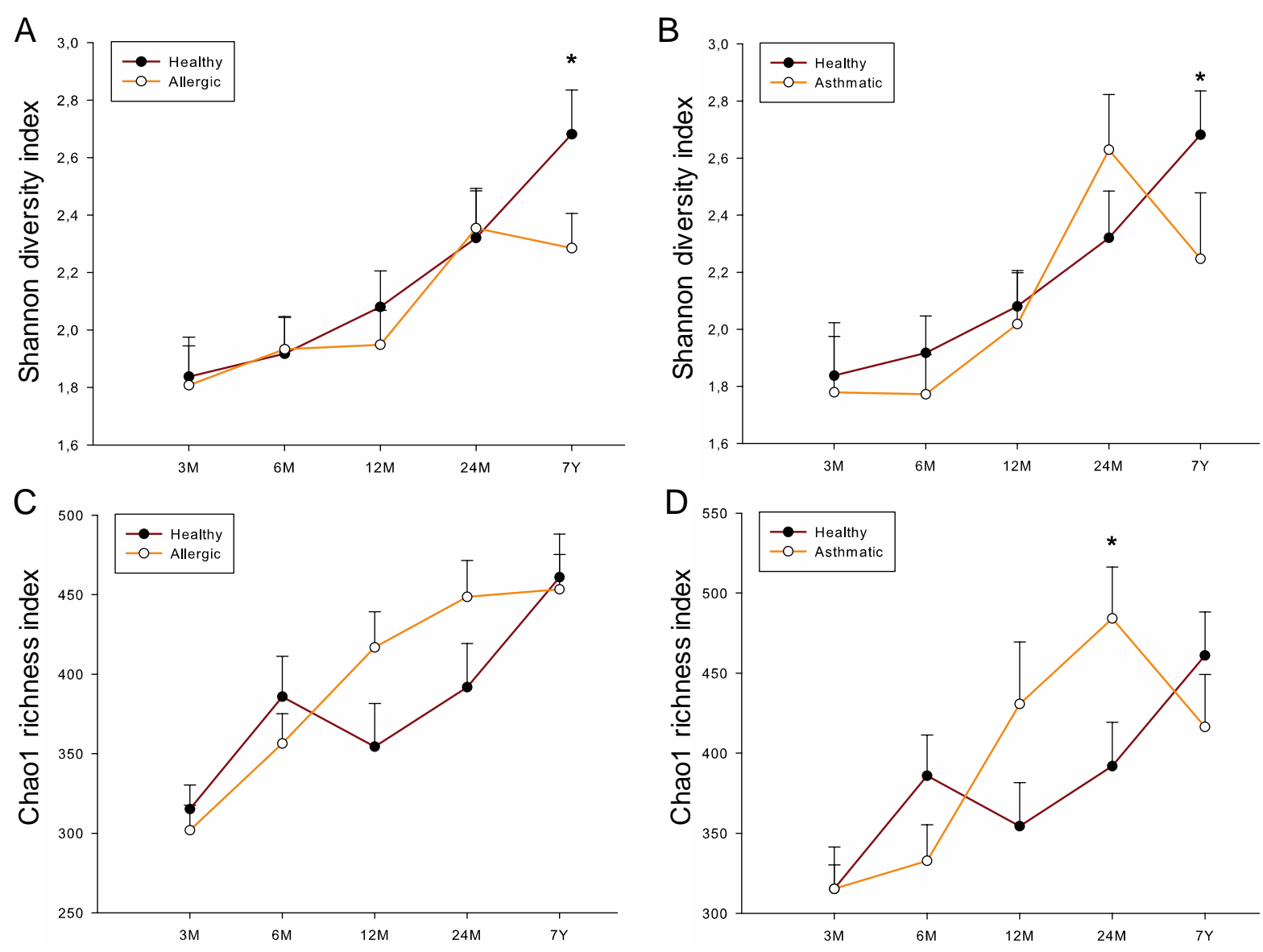

Figure 1.
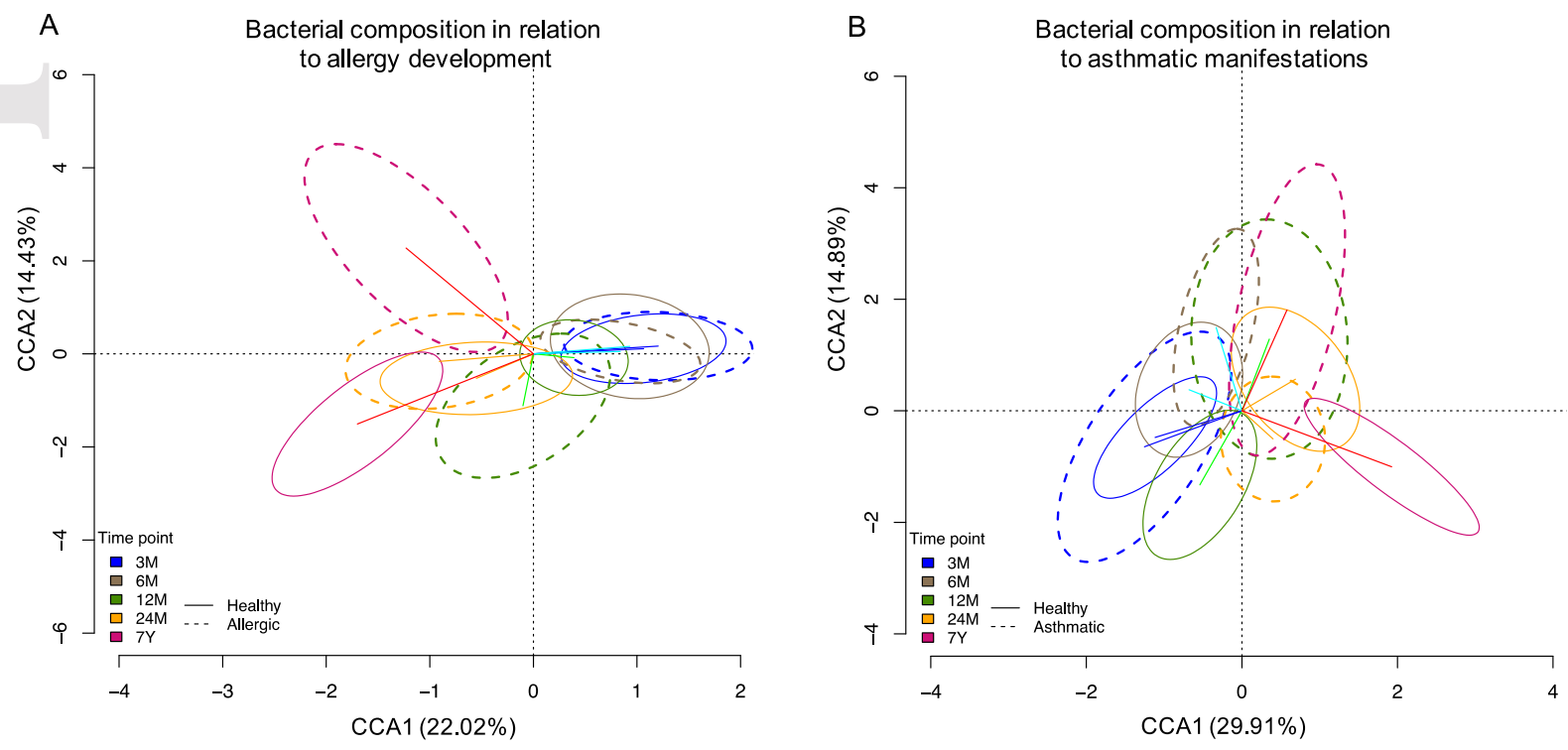

Figure 2.

This article is protected by copyright. All rights reserved. 

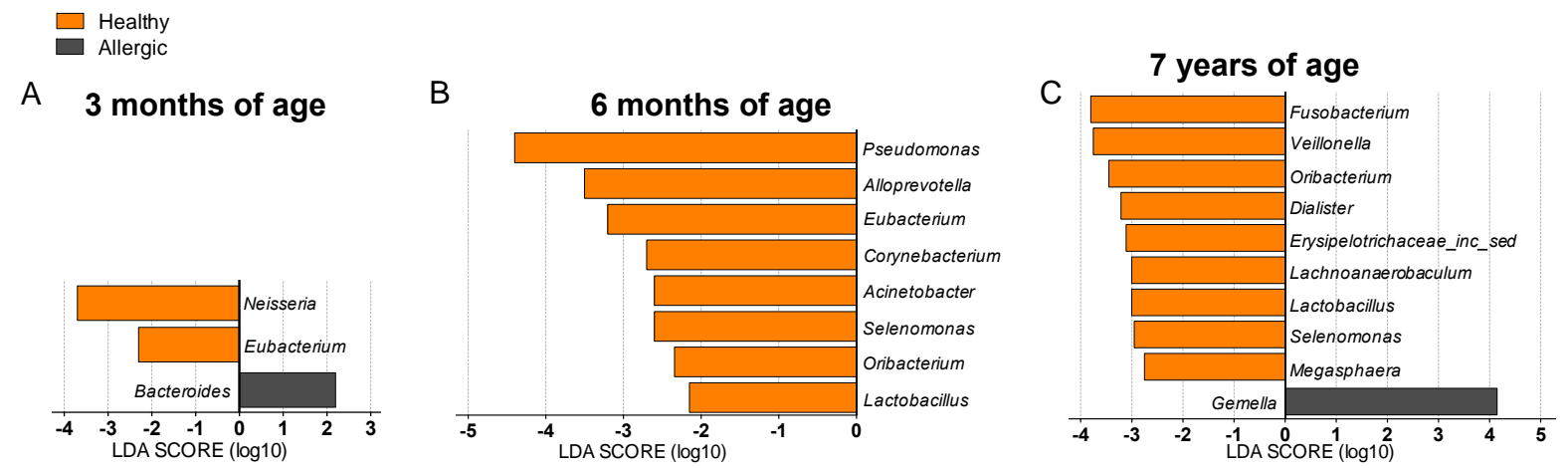

Figure 3.
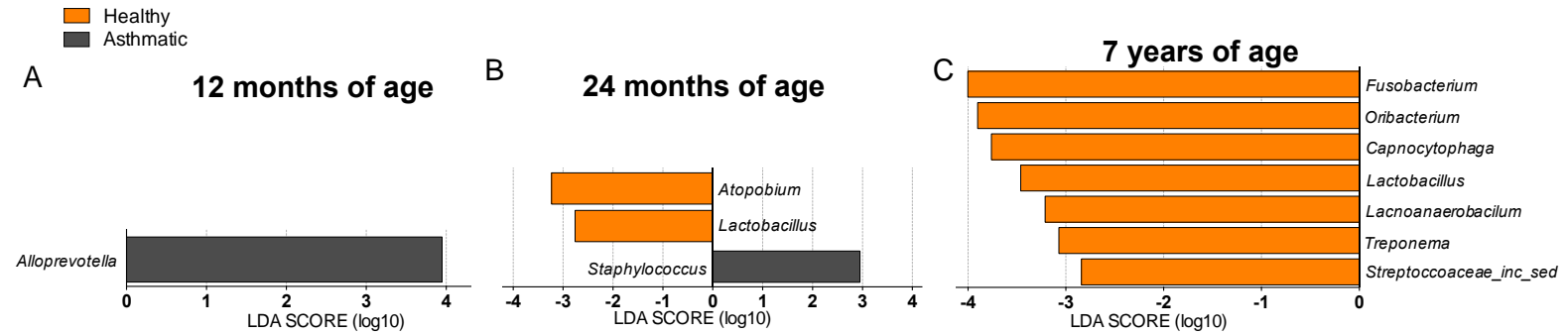

Figure 4.

This article is protected by copyright. All rights reserved. 

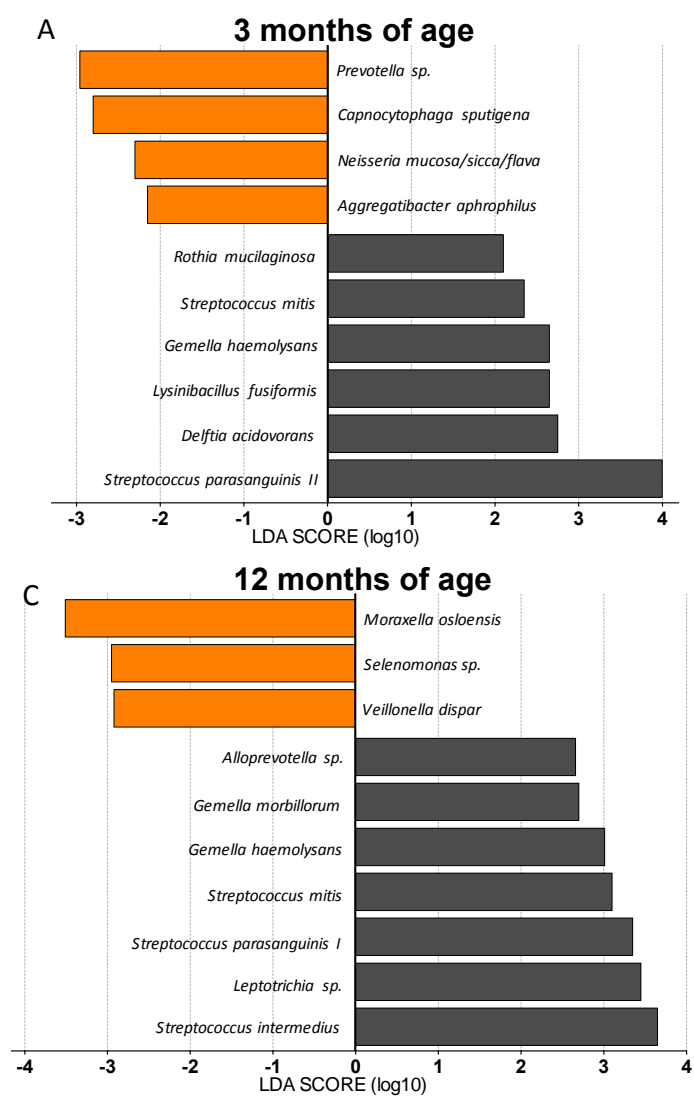

E
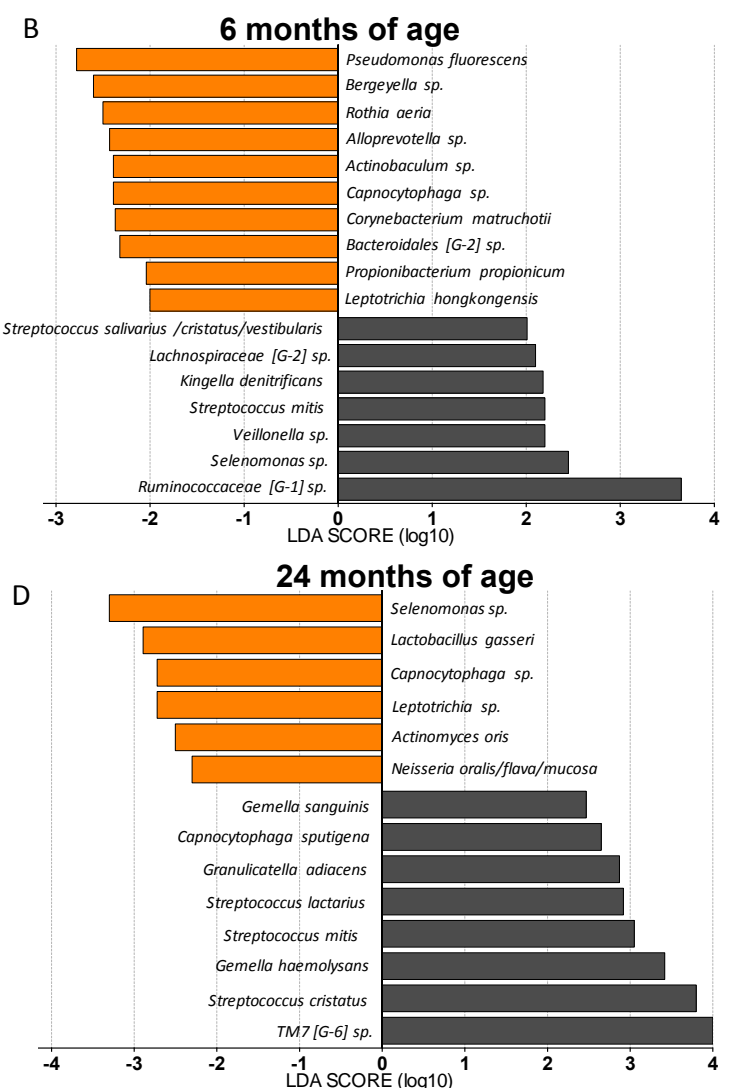

\section{7 years of age}

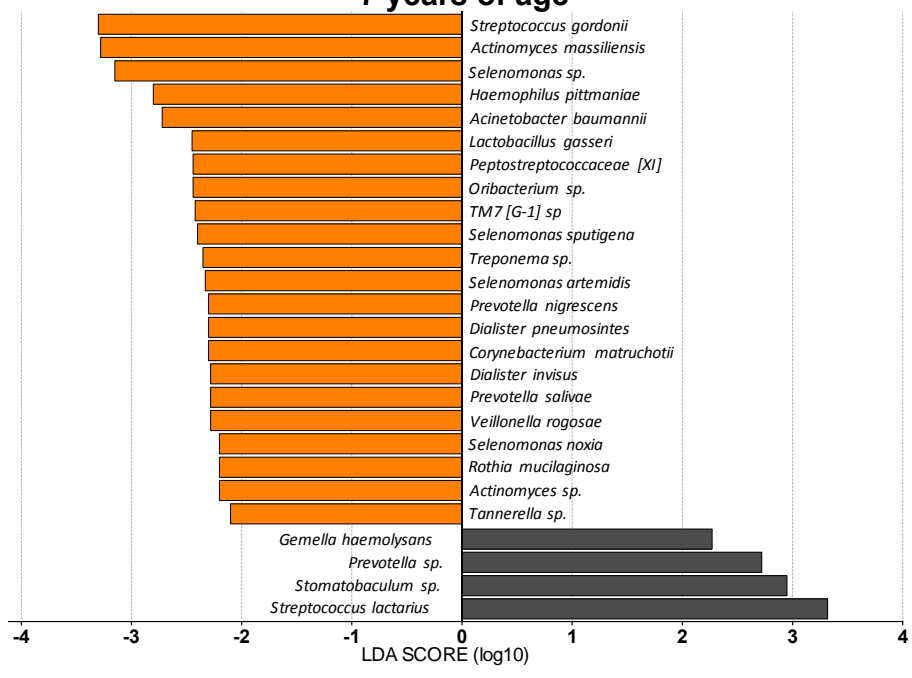

$\square$ Healthy $\square$ Allergic

Figure 5.

This article is protected by copyright. All rights reserved. 


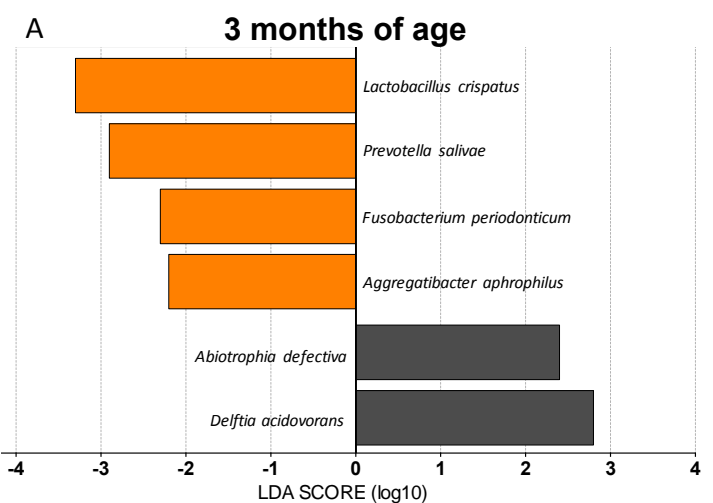

C

12 months of age

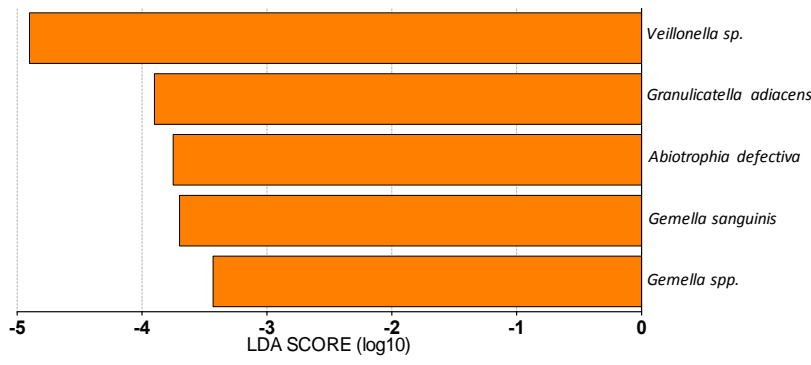

B

6 months of age

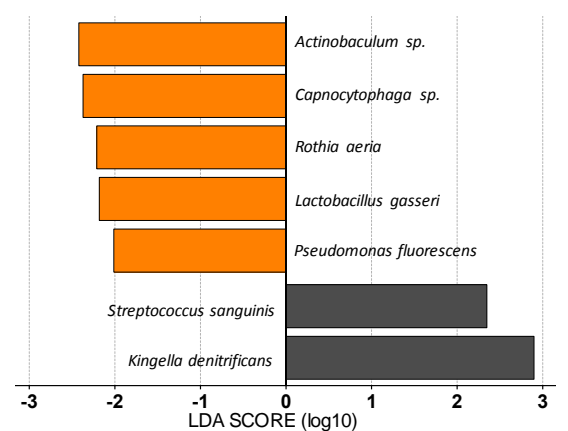

D

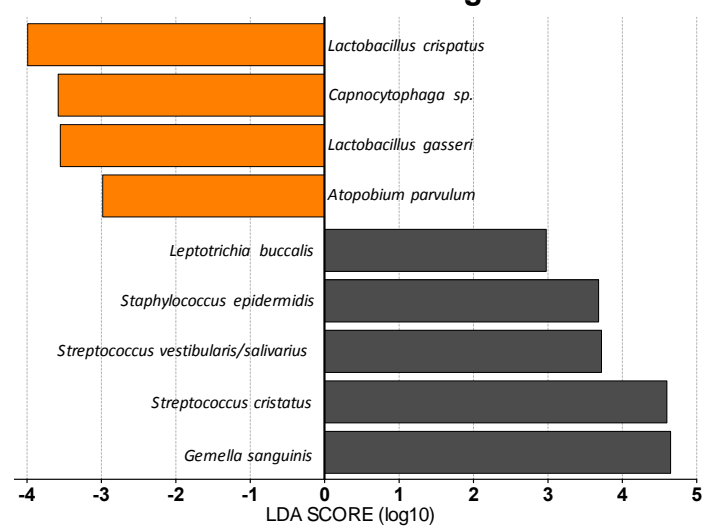

7 years of age

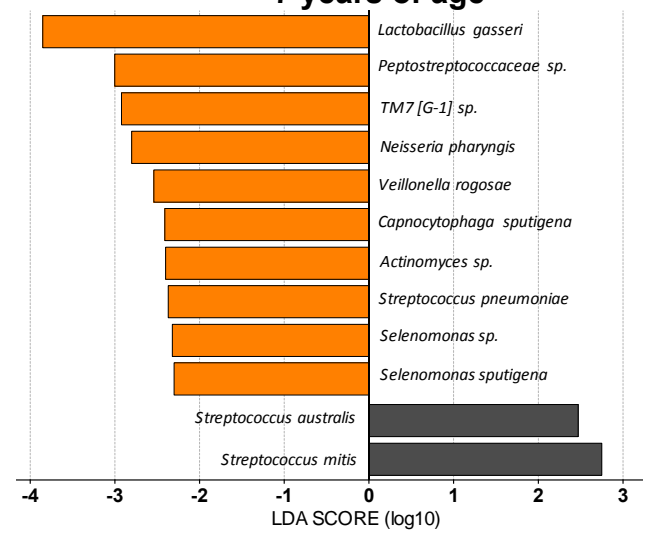

$\square$ Healthy

Asthmatic

Figure 6.

This article is protected by copyright. All rights reserved. 


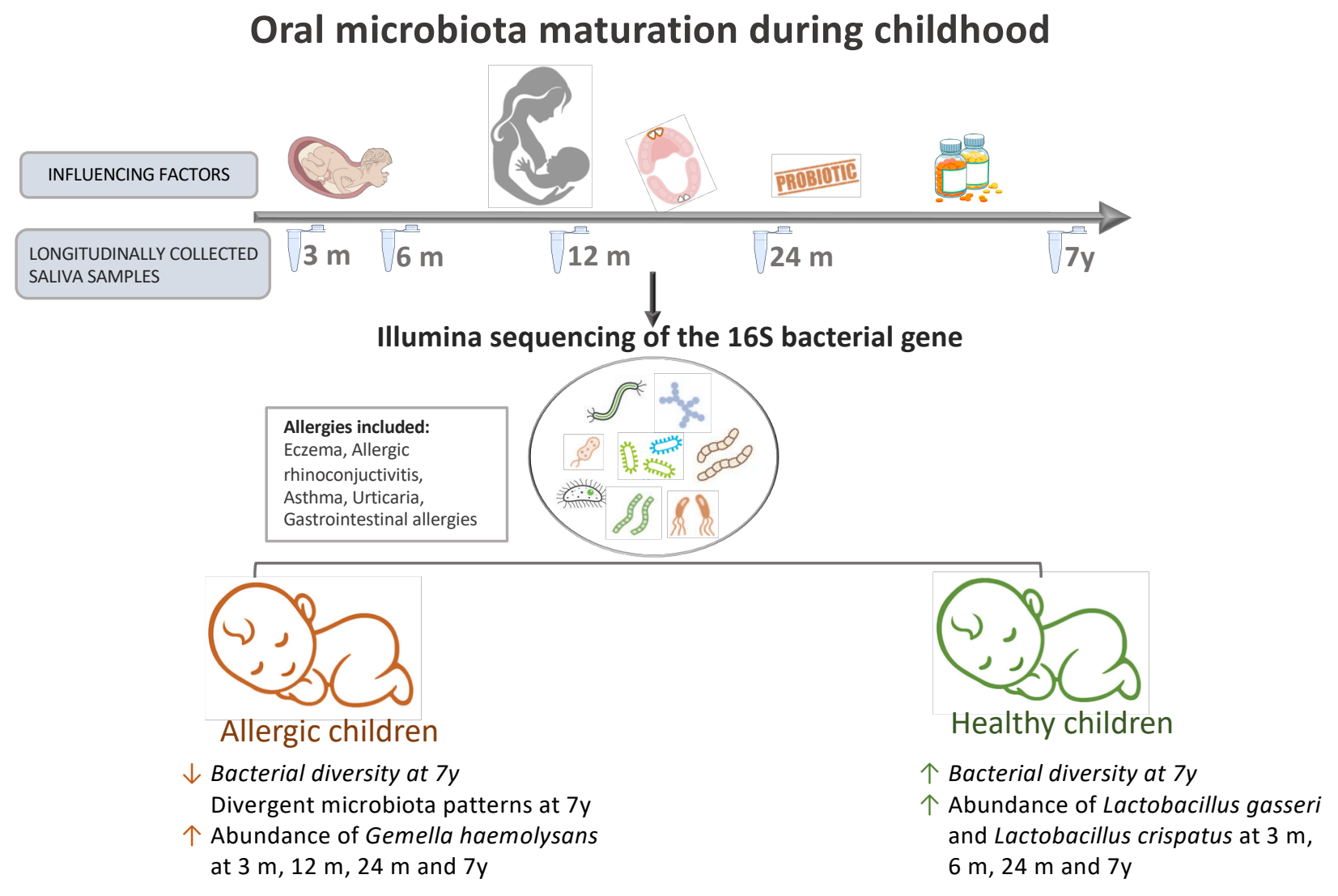




\section{SUPPLEMENTARY MATERIALS}

\section{Oral microbiota maturation during the first 7 years of life in relation to allergy development}

Majda Dzidic $\mathrm{MSc}^{12,3}$, Thomas Abrahamsson $\mathrm{MD}, \mathrm{PhD}^{4}$, Alejandro Artacho BSc ${ }^{2}$, Maria

Carmen Collado $\mathrm{PhD}^{\prime}$, Alex Mira $\mathrm{PhD}^{2}$ and Maria $\mathrm{C}$ Jenmalm $\mathrm{PhD}^{*_{3}}$

\section{METHODS}

\section{Sample collection and study design}

The infants included in this study were part of a larger randomized double-blind trial in southeastern Sweden, recruiting participants between 2001 and 2003, where the potential allergy prevention effect of probiotic Lactobacillus reuteri ATCC 55730 until 2 and 7 years of age was evaluated.(1,2) Among the 188 infants completing the original study, longitudinal salivary samples were collected at 3, 6,12 and 24 month and 7 years of age in 47 children developing allergic symptoms and 33 children staying healthy up to 7 years of age. The selection of saliva samples for this study was based on sample availability. The included children were not statistically different from the children included in the main trial with regards to the variables presented in Table 1. The participants were instructed not to eat or drink for two hours preceding the sampling. Non-stimulated saliva samples were collected from the buccal cavity, using a hand pump (Nalgene \#6131, ThermoFisher, Stockholm, Sweden) connected to a thin plastic tube, and immediately frozen and kept at $-20^{\circ} \mathrm{C}$. In connection with the oral examination and saliva sampling, clinical data about symptoms of allergic disease, adverse events, infections, use of antibiotics, and possible confounding factors were registered.(1, 2) Infants were regarded as sensitized if they had at least one positive skin prick test and/or detectable circulating allergen specific-IgE antibodies.(1, 2) Skin prick tests were performed on the forearm with egg white, fresh skimmed cow milk and standardized cat, dog, birch, peanut, mite (Der p) and timothy extracts. (2) Moreover, symptoms related to allergic disease, physical examination, spirometry and measurement of fractional exhaled nitric oxid $\left(\mathrm{FE}_{\mathrm{No}}\right)$ were observed. Children were diagnosed with allergy if they have had symptoms of and/or have been treated for the actual allergic disease during the last twelve months. Asthma diagnosis was based on at least one of following two criteria: 1 . Doctor diagnosis and asthma symptoms and/or medication during the last twelwe months; 2 . Wheeze or nocturnal cough and a positive reversibility test and/or pathological $\mathrm{FE}_{\mathrm{N}}$ value.(1, 
3) All asthmatic children were also included in the allergic group. For further details, please see the publications from Abrahamsson T. et al.(1-3)

Possible confounders, such as mode of delivery, breastfeeding, probiotics supplementation, maternal allergy and antibiotics use during the first two years of age were obtained from medical records and questionnaires (see Table I). $90 \%$ and $77 \%$ of all the children included were exclusively breast-fed up to 1 and 3 months of age, respectively, and $96 \%$ were partially breastfed at 3 months of age. No infant received antibiotics before 1 month of age and one at 3 months of age.

The studies were approved by the Regional Ethics Committee for Human Research in Linköping, Sweden (Dnr 99323, M122-31 and M171-07, respectively). An informed consent was obtained from both parents before inclusion in the study.

\section{DNA extraction}

$250 \mathrm{ul}$ of saliva sample was centrifuged at $15000 \mathrm{~g}$ for $30 \mathrm{~min}$ and the pellet, together with 50 $\mathrm{ul}$ of the supernatant, were used for further analysis. DNA was isolated with a MagNA Pure LC 2.0 equipment (1996-2016 Roche Diagnostics, Barcelona, Spain), using MagNA Pure LC DNA Isolation Kit III for Bacteria \& Fungi (Roche Diagnostics GmbH, Mannheim, Germany) following the manufacturer's instructions with an additional enzymatic lysis step with lysozyme (20 mg/ml, 37 ${ }^{\circ} \mathrm{C}, 60 \mathrm{~min}$; Thermomixer comfort, Eppendorf, Hamburg, Germany), lysostaphin (2000 units/mg protein, 37 ${ }^{\circ} \mathrm{C}, 60 \mathrm{~min}$; Sigma-Aldrich, Madrid, Spain) and mutanolysin (4000 units/mg protein, $37^{\circ} \mathrm{C}, 60 \mathrm{~min}$; Sigma-Aldrich). DNA was resuspended in $100 \mathrm{ul}$ of elution buffer and frozen at $-20^{\circ} \mathrm{C}$ until further analysis.

\section{S rDNA gene amplification and sequencing}

Prior to sequencing of the $16 \mathrm{~S}$ rDNA gene, extracted DNA was pre-amplified in order to increase total nucleic acid yield by using universal bacterial degenerate primers $8 \mathrm{~F}-$ AGAGTTTGATCMTGGCTCAG and 926R-CCGTCAATTCMTTTRAGT, which encompass the hypervariable regions V1-V5 of the gene. This was performed using the highfidelity AB-Gene DNA polymerase (Thermo Scientific, Waltham, Mass., USA) with an annealing temperature of $52^{\circ} \mathrm{C}$ and 10 cycles, in order to minimize amplification biases.(4) The purification of PCR products was completed using Nucleofast 96 PCR filter plates (Macherey-Nagel, Düren, Germany). 
An Illumina amplicon library was performed following the 16S rDNA gene Metagenomic Sequencing Library Preparation Illumina protocol (Part \#15044223 Rev. A). The genespecific primer sequences used in this protocol were selected from the Klindworth et al. publication and target the 16S rDNA gene V3 and V4 regions, resulting in a single amplicon of approximately $460 \mathrm{bp}$. Overhand adapter sequences were used together with the primer pair sequences for compatibility with Illumina index and sequencing adapters. After $16 \mathrm{~S}$ rDNA gene amplification, the DNA was sequenced on a MiSeq Sequencer according to manufacturer's instructions (Illumina) using the 2x300 bp paired-end protocol.

\section{Bacterial load and measurements with quantitative PCR}

Total bacterial load (bacterial cells per $\mathrm{ml}$ of saliva) in saliva samples was measured by quantitative PCR. Amplifications were performed in duplicates on a LightCycler 480 RealTime PCR System (Roche Technologies) by using annealing temperatures of $60^{\circ} \mathrm{C}$. Each reaction mixture of $10 \mathrm{~mL}$ was composed of SYBR Green PCR Master Mix (Roche), $0.5 \mathrm{~mL}$ of the bacterial universal primer (concentration $10 \mathrm{mmol} / \mathrm{L}$ ), and $2 \mathrm{~mL}$ of DNA template. The forward primer was 5'GTG CCA GCM GCC GCG GTA A 3' and the reverse primer 5'GCG TGG ACT ACC AGG GTA TCT 3' (Integrated DNA Technologies (IDT); San Diego, California, USA), targeting the 16S rDNA gene.(5) The obtained $\mathrm{Ct}$ values were transformed to bacterial cell numbers by a standard curve calibrated by flow cytometry.(6)

\section{Bioinformatics and statistics}

Only overlapping paired end reads were used for analysis. A sequence quality assessment was carried out using the PRINSEQ program. Sequences of $<250$ nucleotides in length were not considered; $5^{\prime}$ trimming was performed by cutting out nucleotides with a mean quality of $<30$ in 20-bp windows. Chimeric $16 \mathrm{~S}$ sequences were filtered out using USEARCH.(7)

Obtained sequences were taxonomically classified by the RDP-classifier (8) where the reads were assigned a phylum, class, family and genus and phylogenetic ranks were allocated when scores exceeded 0.8 confidence threshold. Operational taxonomic units (OTUs) were generated by using CD-HIT OTU picking with 97\% of similarity.(9) Normalized OTU tables were used for downstream analysis. The human oral microbiome database (HOMD) was used as a reference database for OTU assignment.(10)

Microbiota diversity metrics were determined from normalised OTU tables. $\alpha$ - diversity analysis (presented here as Shannon and Chaol indices), were utilized to estimate the 
samples' diversity and richness using the R-package Vegan.(11) Constrained correspondence analysis (CCA, a.k.a. canonical correspondence analysis) is a statistic tool used to emphasize variation, taking advantage of the fact that the factor provided can explain part of the total variability, and bring out strong patterns in a dataset. This analysis was performed by $\mathrm{R}$ software ade4 package (12), using the function $C C A$ (related to correspondence analysis) and based on Chi-squared distances. Furthermore, the Adonis statistic for permutational multivariate analysis was used to measure differences in variance between groups.

Linear discriminant analysis effect size (LEfSe), a method for biomarker discovery on the online interface Galaxy (http://huttenhower.sph.harvard.edu) (13), was used to determine taxa that best characterize the populations of healthy children and children developing allergies. LEfSe scores measure the consistency of differences in relative abundance between taxa in the groups analysed, where a higher score indicates higher consistency. In this study, LEfSe was used for biomarker discovery at both genus and species-level OTUs. The threshold for the logarithmic LDA score was set at 2.0. The influence of confounding factors was determined by the CCA statistic tool and Adonis permutational multivariate analysis.

Statistical analyses were performed in R version 3.2.2 and GraphPad Prism 6 (GraphPad Software, San Diego, CA, USA, Version 6.1f), where $\mathrm{p}<0.05$ was considered significant. Comparison between categories was performed by Mann-Whitney $U$ test. Specific statistical tests are stated in figure legends.

\section{References}

1. Abrahamsson TR, Jakobsson T, Böttcher MF, et al (2007) Probiotics in prevention of IgE-associated eczema: A double-blind, randomized, placebo-controlled trial. J Allergy Clin Immunol 119:1174-1180.

2. Abrahamsson TR, Jakobsson T, Björkstén B, et al (2013) No effect of probiotics on respiratory allergies: a seven-year follow-up of a randomized controlled trial in infancy. Pediatr Allergy Immunol 24:556-561.

3. Abrahamsson TR, Jakobsson HE, Andersson AF, et al (2014) Low gut microbiota diversity in early infancy precedes asthma at school age. Clin Exp Allergy 44:842-850.

4. Sipos R, Székely AJ, Palatinszky M, et al (2007) Effect of primer mismatch, annealing temperature and PCR cycle number on $16 \mathrm{~S}$ rRNA gene-targetting bacterial community analysis. FEMS Microbiol Ecol 60:341-350.

5. Aminov RI, Garrigues-Jeanjean N, Mackie RI (2001) Molecular Ecology of Tetracycline Resistance: Development and Validation of Primers for Detection of Tetracycline Resistance Genes Encoding Ribosomal Protection Proteins. Appl Environ Microbiol 67:22-32. doi: 10.1128/AEM.67.1.22-32.2001 
6. Boix-Amorós A, Collado MC, Mira A (2016) Relationship between Milk Microbiota, Bacterial Load, Macronutrients, and Human Cells during Lactation. Front Microbiol 7:492.

7. Edgar RC (2017) Updating the 97\% identity threshold for 16 S ribosomal RNA OTUs. doi.org 192211. doi: 10.1101/192211

8. Cole JR, Wang Q, Fish JA, et al (2014) Ribosomal Database Project: data and tools for high throughput rRNA analysis. Nucleic Acids Res 42:D633-42.

9. Li W, Godzik A (2006) Cd-hit: a fast program for clustering and comparing large sets of protein or nucleotide sequences. Bioinformatics 22:1658-1659.

10. Chen T, Yu W-H, Izard J, et al (2010) The Human Oral Microbiome Database: a web accessible resource for investigating oral microbe taxonomic and genomic information. Database (Oxford) 2010:baq013.

11. Jari Oksanen, F. Guillaume Blanchet, Michael Friendly, Roeland Kindt, Pierre Legendre, Dan McGlinn, Peter R. Minchin, R. B. O’Hara, Gavin L. Simpson, Peter Solymos, M. Henry H. Stevens and Eduard Szoecs HW (2017) vegan: Community Ecology Package.

12. Dray S. and Dufour AB. (2007) The ade4 package: implementing the duality diagram for ecologists. J Stat Softw 22:1-20.

13. Segata N, Izard J, Waldron L, et al (2011) Metagenomic biomarker discovery and explanation. Genome Biol 12:R60. 


\section{RESULTS}
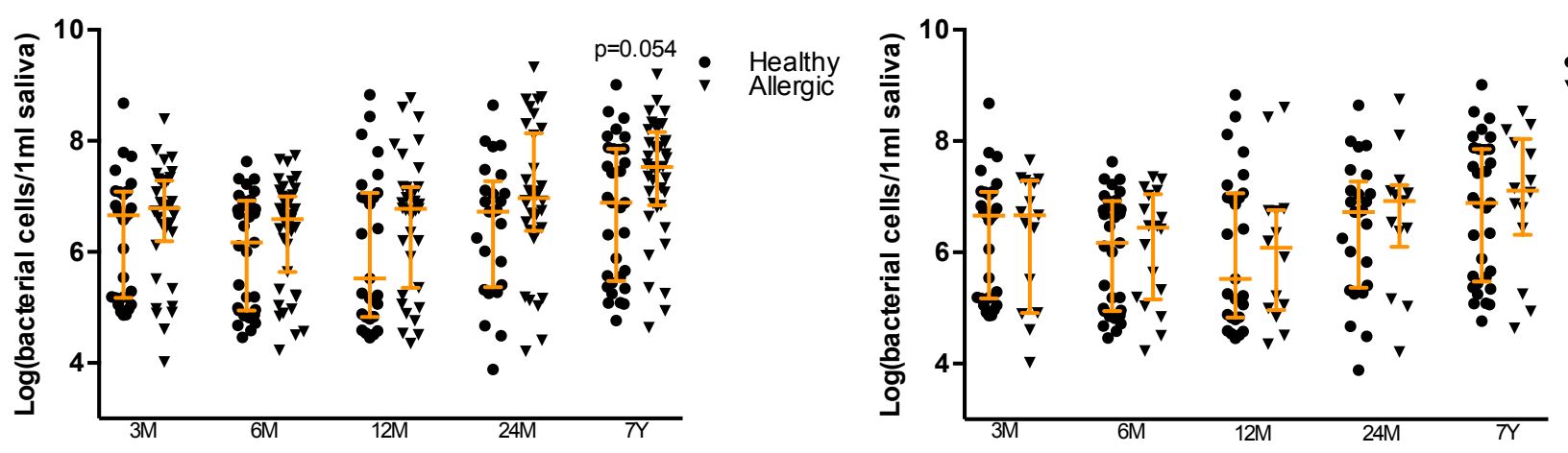

Figure S1. Bacterial load in infant saliva samples. Bacterial density in salivary samples, obtained at different time points until 7 years of age, was determined by qPCR using universal primers targeting the $16 \mathrm{~S}$ bacterial gene. Figures show number of bacterial cells $/ \mathrm{ml}$ in allergic (A) and asthmatic children (B) when compared to children staying healthy up to 7 years of age. Children developing allergies tended to have higher levels of bacterial load at 7 years of age ( $\mathrm{p}=0.054)$, when compared to children staying healthy (A). Data are presented with median with interquartile ranges. Mann-Whitney U-test was used for statistical comparisons. 3 months

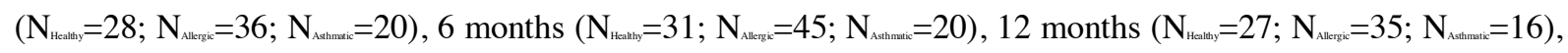

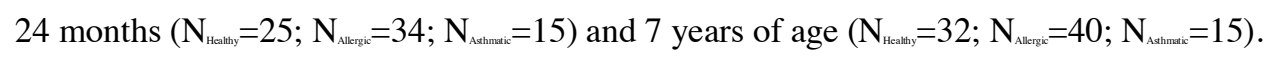




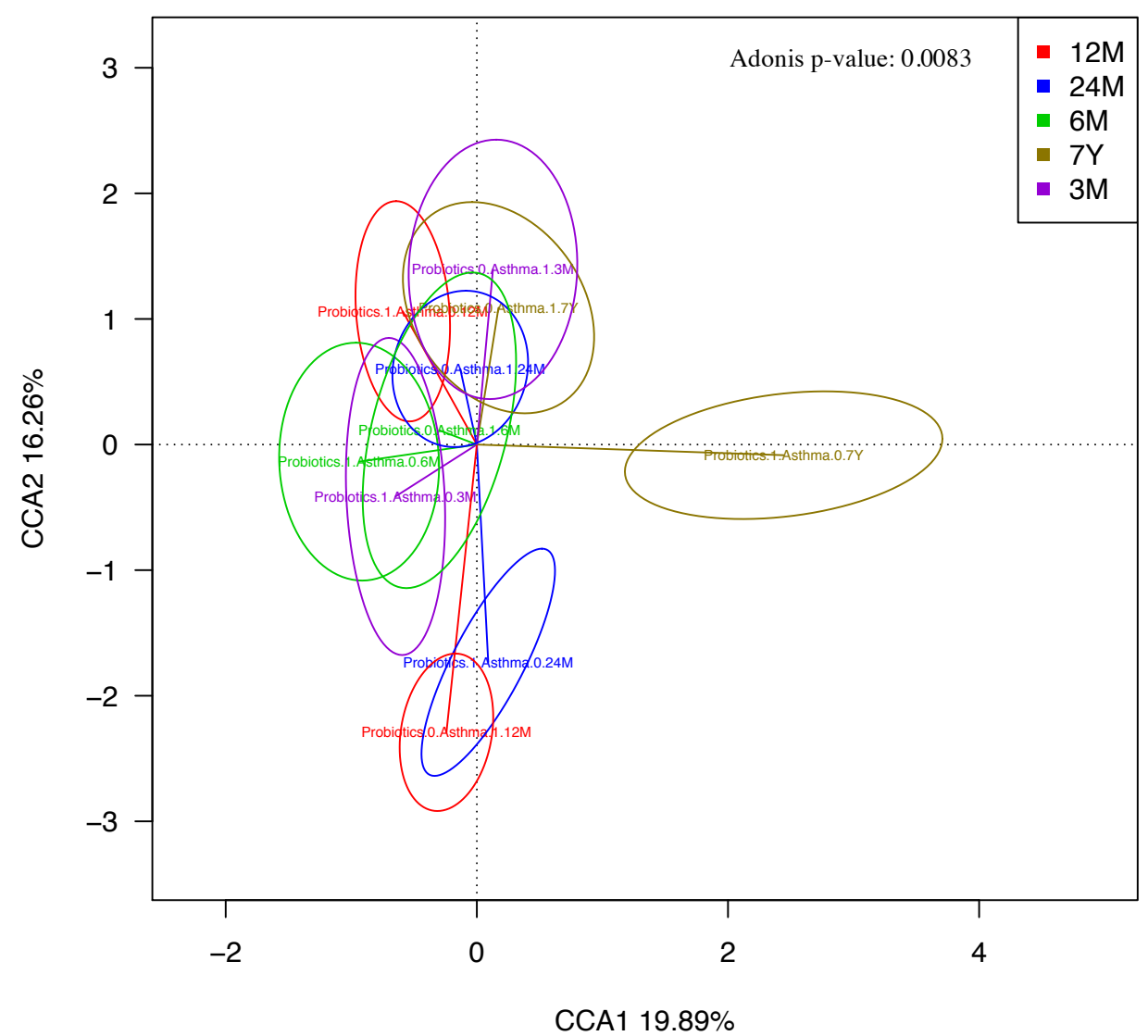

Figure S2. The effect of probiotic supplementation with Lactobacillus reuteri on the oral microbiota composition in relation to asthma development. Constrained correspondence analyses (CCA), here used to emphasize variations in microbiota species-level patterns, show compositional characteristics of total microbiota at different time points. The percentage of variation explained by constrained correspondence components is indicated on the axes. The plot is showing the impact of probiotic supplementation, during early infancy, on the oral microbiota composition in saliva samples collected at 3, 6, 12, 24 months and 7 years of age in children staying healthy and children developing asthmatic manifestations $(\mathrm{p}=0.0083)$. Different colours present different time points ( $\mathrm{M}=$ Months, $\mathrm{Y}=$ Years) and probiotic supplementation in children and asthma development are marked with either 0 or 1 describing the absence or presence, respectively. $\mathrm{p}$ values for CCA plots were determined by Adonis and indicate if the factor provided (in this case time) can

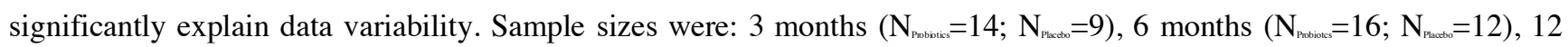

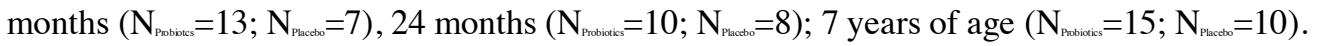

